\title{
APRESENTACÃOA
}

\section{Claudia Fonseca*}

Denise F. Jardim **

Patrice Schuch ${ }^{* * *}$

Universidade Federal do Rio Grande do Sul - Brasil

Helena Machado ${ }^{* * * *}$

Universidade de Coimbra - Portugal

\section{Tecnologias de governo: apreciação e releituras em antropologia}

[Damiens fora condenado, a 2 de março de 1757], a pedir perdão publicamente diante da porta principal da Igreja de Paris, aonde devia ser levado e acompanhado numa carroça, nu, de camisola, carregando uma tocha de cera acesa de duas libras; em seguida, na dita carroça, na praça de Grève, e sobre um patíbulo que aí será erguido, atenazado nos mamilos, braços, coxas e barrigas das pernas, sua mão direita segurando a faca com que cometeu o dito parricídio, queimada com fogo de enxofre, e às partes em que será atenazado se aplicarão chumbo derretido, óleo fervente, piche em fogo, cera e enxofre derretidos conjuntamente, e a seguir seu corpo será puxado e desmembrado por quatro cavalos e seus membros e corpo consumidos ao fogo, reduzidos a cinzas, e suas cinzas lançadas ao vento. Finalmente foi esquartejado [relata a Gazette d'Amsterdam]. Essa ultima operação foi muito longa, porque os cavalos utilizados não estavam afeitos à tração; de modo que, em vez de quatro, foi preciso colocar seis; e como isso não bastasse, foi necessário, para desmembrar as coxas do infeliz, cortar-lhe os nervos e retalhar-lhe as juntas. (Foucault, 1987, p. 9).

Publicado originalmente em 1975, é com as palavras acima que se inicia o livro Vigiar e punir, de Michel Foucault. O detalhamento minucioso das

\footnotetext{
* Contato: claudialwfonseca@gmail.com

** Contato: denisejardim.ufrgs@gmail.com

*** Contato: patrice.schuch@gmail.com

**** Contato: helenamachado@ces.uc.pt
} 
práticas de punição infligidas a Damiens em 1757 - a tortura nos seus braços, mamilos, coxas e barrigas das pernas, a queimadura de sua mão direita, a aplicação de chumbo fervente nas feridas, o desmembramento e esquartejamento dos nervos e juntas de seu corpo - assusta e horroriza leitores contemporâneos. Ao mesmo tempo em que tal descrição comove, ela é produtiva, pois é exatamente através da atenção às técnicas de produção das "mil mortes" infligidas a Damiens que Foucault insere, no campo das ciências, um conjunto de novas problematizações acerca das relações entre poder, saber e verdade. Como ele próprio assinala, o livro pode ser lido como um pano de fundo histórico sobre o poder de normalização e sobre a formação de saber na sociedade moderna (Foucault, 1987). Seus personagens principais: o suplício, a guilhotina, a prisão. É a transformação dessas técnicas de punição e seu desenvolvimento que viabilizam um novo conjunto de interesses analíticos: as tecnologias de poder - engrenagens, focos, instrumentos técnicos, projetos, enfim, meios destinados à consecução de determinado fim (Ong, 2003; Ong; Collier, 2005; Rose, 1999) - interrogadas em sua dimensão positiva: o que produzem? Quais seus efeitos? Como acontecem?

Não é nosso interesse realizar uma digressão teórica em torno da obra foucaultiana, tarefa já realizada por outros pesquisadores. Entretanto, é importante reter, na apresentação deste número de Horizontes Antropológicos, a relevância analítica das tecnologias de poder e um processo fundamental que se realiza a partir desse investimento na minúcia das práticas e nas engrenagens do poder: a ampliação do estatuto do político na vida social (Dirks; Eley; Ortner, 1993). Para antropólogos e antropólogas, isso oportunizou o reforço de uma agenda de pesquisas que conta com forças crescentes de problematização, como os estudos pós-coloniais e os estudos feministas. Interessar-se por tecnologias de poder significa pôr em questão conjuntos diversos de constituição de verdades e saberes que passam a ser vistos como sempre investidos por relações de poder e nada têm de neutros. Por outro lado, o funcionamento da microfísica das relações de poder exige um redimensionamento de noções antropológicas clássicas, como de cultura e de sociedade, incluindo-se também nessas reflexões os próprios modos de constituição disciplinar e os modos localizados de objetivação da ciência (Abu-Lughod, 1991; Asad, 1973; Fabian, 2013; Haraway, 1991; Latour, 2005; Said, 1990).

Tomadas como formas de intervenção destinadas a guiar, dirigir, orientar, capacitar e regular os sujeitos, populações e problemáticas, as tecnologias 
de governo são examinadas por antropólogos e antropólogas a partir de universos de pesquisa, tais como os que aparecem neste número da revista, que só recentemente entraram na mira da antropologia: práticas científicas e diagnósticas, lógicas administrativas da intervenção a populações, burocratas e burocracias, a constituição de sujeitos e processos de subjetivação, práticas etnopolíticas na efetivação de direitos de cidadania, etc. Se a potência de uma noção de poder que opera também a partir das engrenagens cotidianas investe as pesquisas antropológicas de novos desafios, simultaneamente possibilita uma refuncionalização da etnografia no estudo de temas como os processos de constituição do Estado e da lei. Ao enfatizar as dinâmicas sempre inconclusas e a cotidianidade de saberes, operações e procedimentos que fazem o Estado ordinariamente (Das; Poole, 2004) ou mesmo o efeito de sua solidez e centralidade, realizado a partir de técnicas, procedimentos e formas repetitivas e operativas específicas (Mitchell, 1999; Sharma; Gupta, 2006), as etnografias vêm contribuindo, na articulação com outras disciplinas, para a problematização de perspectivas muito homogêneas ou transcendentes sobre a constituição e funcionamento do poder.

Esta coletânea consiste assim em um desafio, pois conclama o leitor a sair das cômodas abstrações do "Estado" e suas entranhas, para examinar o modo como os dispositivos de poder são globalizados e capilarizados em diferentes sociedades. Salta aos olhos, a partir dos estudos neste número, que há algo a ser refletido nas práticas de interpelação das tecnologias de governo - não mais como mero cenário no qual nossos interlocutores se situam, mas como elas próprias personagens dotadas de formas de expressão que instalam arenas de recursividade e modos de atuação.

Dar visibilidade às tecnologias de governo em campos de pesquisa muito diversos, por vezes, em uma mesma experiência nacional é também uma forma de inspecionar a diversidade de empregos e força criativa de tais tecnologias. Por certo, não significa, através desta coletânea, revitalizar os fantasmas que já conhecemos e as críticas que já foram dirigidas ao programa de pesquisa foucaultiano. Significa antes evitar cair na armadilha da reificação dos conceitos de poder e tecnologias de controle e abrir novas interlocuções e modos de revisitar experiências etnográficas levando em consideração as tecnologias de governo e o modo como, na atualidade, incidem na vida humana (Latour, 2005). 


\section{Algumas renovacões conceituais: políticas da vida e o devir}

Uma abundância de materialidades e exemplos históricos e historicizantes sobre os dispositivos de poder na gestão de populações passam a fazer parte do repertório corrente dos estudos antropológicos. A ideia de tecnologias de governo conclama as pesquisas etnográficas a compreender a "conduta sobre a conduta" (Foucault, 1979) em tramas dinâmicas de saberes, poderes e verdades entrecruzadas, que são sempre receptivas a novos especialismos e ao exercício de um feixe de forças assistemático, embora potente. O termo tecnologias de governo contrasta sobremaneira com a ideia amplamente manejada de "governança", que parece imaginar uma sistematicidade das relações e lógicas de governo e, muitas vezes, relaciona-se com o ideal de um aperfeiçoamento de tais sistemas via linhas de atuação direta na administração de Estados, percebidos, eles próprios, como também sistemáticos e homogêneos. Estudos etnográficos embasados pela noção de tecnologias de governo, ao contrário, percebem o Estado, ele próprio, como um resultado das tecnologias de poder (Deleuze, 1987; Foucault, 2008) e não como um ente transcendente em relação a estas. Isso significa uma atenção redobrada nas técnicas, engenharias, engrenagens, materialidades e mediações diversas em que as relações de poder funcionam e se exercem.

Se de um lado é possível destacar as contribuições antropológicas importantes na problematização da agência dos sujeitos e suas interpretações em processos de mediação em torno das artes de governar que não têm nada de totalizante, por outro lado a potência das pesquisas etnográficas no estudo das tecnologias de governo vem conduzindo a renovações conceituais importantes. Didier Fassin é um dos autores de destaque nesse âmbito porque, a partir das etnografias que realiza, vem inovando o próprio repertório conceitual dos estudos sobre modos de governo. Em pesquisas tão diversas como aquelas realizadas acerca das práticas humanitárias (Fassin, 2007a, 2010; Fassin; Pandolfi, 2010), programas franceses de auxílio a necessidades e a pessoas sem documentos (Fassin, 2007a), políticas de combate à AIDS na África do Sul (Fassin, 2007b) e patrulhamento policial em periferias francesas (Fassin, 2011), o autor torna explícitos os modos de avaliação e diferenciação de vidas, assim como a análise das desigualdades daí decorrentes, integrando a etnografia com as dimensões política e histórica. Tais modos de valorar e diferenciar 
vidas estão expressos e constituídos por meio de discursos, tecnologias e dispositivos de avaliação e diferenciação, além de modos de subjetivação e subjetividades.

A partir de Fassin, noções como "economia moral", "biolegitimidade" e "políticas da vida" passam a compor um novo repertório analítico-conceitual que não funciona para traçar quadros estáveis de sentidos ou representações culturais - por exemplo, aquelas pelas quais a explicação do avanço assustador da AIDS na África do Sul seria resultado de crenças e valores culturalmente engendrados. Tais conceitos são, ao contrário, ferramentas de inteligibilidade do que Fassin refere como a dimensão ética das "políticas da vida", isto é, as relações entre o valor da vida como um bem supremo e o valor das vidas, nas existências concretas dos seres humanos. O conceito nasce em estreito diálogo produtivo com a obra de Michel Foucault, a quem reconhece débito, mas destaca uma forma de aproximação cada vez mais crítica (Fassin, 2009). O foco inclusivo da experiência e das narrativas dos atores sociais é, de certo modo, um eixo diferenciador no trabalho de Fassin, pois, para o autor, tais agentes não se reduzem a sujeitos construídos discursivamente ou, em uma dobra (Deleuze, 1987), a sujeitos produtores de verdades de si. Além de tudo isso, os sujeitos experimentam o mundo social em sua complexidade e agência.

Na pesquisa sobre as políticas em relação à AIDS na África do Sul, por exemplo, longe de falar da doença apenas como uma fatalidade biológica ou curiosidade cultural, as narrativas revelavam os efeitos de desigualdades políticas e violências históricas. Entretanto, para Fassin (2007b), elas mostravam também como a patologia podia tornar-se um instrumento para a própria reconstrução do self e dos modos de vida daqueles afetados. Ao afirmarem a "vida", produzem a sua significação moral e política, tornando problemática a rigidez objetivante de abordagens analíticas que homogeneízam os sujeitos. Trata-se, portanto, de incluir não somente a experiência dos atores, mas também a dimensão dos "valores" e "significados" na produção da vida, o que o autor realiza a partir de seus clamores por uma "antropologia moral" (Fassin, 2008,2012 ) e da ênfase na noção de "biolegitimidade". Isto é, interessa problematizar o modo como seres humanos são tratados e têm suas vidas avaliadas e distinguidas, não somente por tecnologias de governo, mas também por dimensões morais relativas à produção dos significados e pela vivência de suas experiências biográficas e coletivas. Conforme Fassin (2009, p. 52, tradução nossa): "essas perspectivas não são contraditórias, mas complementares: ao 
analisar as novas formas da arte de governo, pode-se apreender o seu conteúdo político". Diz o autor:

O que as políticas fazem para a vida - e as vidas - não é apenas uma questão de discursos, estratégias e táticas. É também uma questão dos modos concretos pelos quais os indivíduos e grupos sociais são tratados, segundo quais princípios e em nome de qual moral, implicando-se nisso desigualdades e falsos reconhecimentos. Em outras palavras, para prolongar a referência wittgensteiniana, é ainda uma questão de forma, mas é também uma questão de vida. (Fassin, 2009, p. 57, tradução nossa).

A emergência de novos repertórios analíticos no estudo das tecnologias de governo também encontra importante referência nas obras de João Biehl, autor que, neste número da revista, entrevistamos. Com panos de fundo semelhantes - os circuitos de cuidado e as novas configurações de poderes nacionais e globais que engendram processos de vida ou morte e envolvem o incremento das tecnologias farmacêuticas e de seu mercado no Brasil, a transformação na gestão do Estado e as práticas de construção da cidadania no país - as ricas etnografias realizadas pelo autor acrescentam ao estudo das tecnologias de governo a atenção para o emergente, inacabado e incompleto: "a people yet to come" (Biehl, 2008).

Tomando a influência da abordagem de Gilles Deleuze sobre poder, Biehl desloca a analítica das relações de poder e sua preeminência, na medida em que acompanha Deleuze $(1994,1996)$ na crítica à noção foucaultiana de poder e seu privilégio em relação aos contínuos vazamentos e extravasamentos do social. A noção de resistência, nessa abordagem, perde o sentido, uma vez que são as indeterminações que têm precedência analítica, em emergentes processos nos quais, encruzilhadas entre subjetividades, tecnologias de governo e linhas de fuga podem ser percebidas em processos de desterritorialização e territorialização contínuos.

A atenção ao devir manifesta-se, na sua pesquisa sobre os processos de abandono social, através do investimento em primeiro plano em Catarina, uma mulher que o autor conheceu em um centro de assistência onde ela encontrava-se internada (Biehl; Eskerod, 2005). Tratada como louca e tendo sua voz quase calada por diagnósticos psiquiátricos diversos, Catarina reivindicava que sua doença era fisiológica. Articulando sua experiência passada e presente, expressava-se através do que chamava de "dicionário", uma lista de termos 
à primeira vista desconexos a que Biehl, ao explorar os circuitos pregressos de Catarina em suas relações familiares, médicas e sociais, acaba reconstituindo a inteligibilidade. Ao expandir seu universo de significação e rearticular o "dicionário" e as falas de Catarina com processos diversos - a persistente desigualdade da sociedade brasileira, as condições de assistência e tratamento de pobres e miseráveis, a política de desinstitucionalização de doentes mentais e o paralelo crescimento da indústria farmacêutica e da medicalização dos pacientes na década de 1990 -, Biehl nos apresenta finalmente Catkine, nome que Catarina dá a si mesma ao subjetivar-se a partir do remédio Akineton, indicado para controlar os efeitos colaterais dos antipsicóticos.

Catkine pode ser considerada a versão etnográfica da interrogação antropológica que guiou Biehl na sua pesquisa - e que permanece como uma inquietação central também na sua pesquisa sobre as políticas da AIDS no Brasil (Biehl; Eskerod, 2007): como certas tecnologias, sistemas de valores e fatores políticos e econômicos se articulam na formação de novas subjetividades, de modo a reconfigurar processos de vida e morte? Em Will to live: AIDS therapie sand the politics of survival (Biehl; Eskerod, 2007), é Luís que contribui ao se apresentar: "A medicação sou eu." Estigmatizado pela família e amigos após o diagnóstico de AIDS, encontrou abrigo numa instituição para acolhimento de pessoas abandonadas com AIDS, na Bahia, chamada Caasah. A instituição foi fundada em 1992 por um grupo de moradores de rua com AIDS, que se apossaram de um prédio de uma maternidade desativada na periferia de Salvador. Ao longo de sua existência, a Caasah virou uma organização não governamental, recebendo financiamento do Banco Mundial e realizando parcerias com instituições municipais e estaduais. Nesse percurso, a original "casa de apoio" virou "casa de passagem", o que significou uma reconfiguração das tecnologias de atendimento aos usuários em sentido amplo: uma progressiva profissionalização dos serviços, medicalização dos (dessa forma) "pacientes" e um investimento na educação de seus sentidos e sensibilidades para o autocontrole e transformação da vida. Como efeito desse processo, há o abandono progressivo do público originalmente atendido pela Caasah, persistindo no atendimento apenas aqueles que, tal como Luís, realizam esforços extraordinários para sobreviver, via processos de autotransformação instigados por uma subjetividade marcada pela importante "vontade de viver".

Arguindo pela importância de uma compreensão cartográfica da subjetividade (Biehl; Locke, 2010; Deleuze, 1994, 1996), Biehl renova a relevância 
analítica desse conceito, contando com as já referidas inspirações do filósofo Gilles Deleuze. Segundo Biehl, a abordagem cartográfica da subjetividade torna-se um antídoto contra qualquer percepção naturalista ou ontológica de sujeito, assim como também para uma noção estritamente culturalista de agência ou, mesmo, para construções do sujeito que partem somente das redes discursivas que o engendram. Trata-se de privilegiar, ao contrário, os processos de formação dos sujeitos - como Catkine e Luís - realizados através de seus acoplamentos com tecnologias e economias morais e políticas, assim como as cartografias emergentes percorridas pelos sujeitos, que se tornam visíveis nas próprias produções subjetivas dos sujeitos que estão "sempre por fazer". Seguindo a trilha deleuziana, Biehl entende que as subjetividades nos dão acesso tanto às encruzilhadas colocadas por diversos dispositivos de poder como também às escolhas dos sujeitos que são realizadas constantemente, em que pesem os grandes determinismos (Biehl; Locke, 2010; Deleuze, 1994, 1996). Este entendimento da subjetividade se coaduna com a proposta de uma "antropologia do devir" (Biehl, 2008), que Biehl explica na entrevista que apresentamos neste número, fazendo questão de ressaltar a contribuição da etnografia para desafiar a metafísica das políticas de intervenção, ao mesmo tempo em que faz destas um campo profícuo de renovação do trabalho antropológico.

\section{Uma antropologia das "impurezas"}

A partir dos artigos deste número de Horizontes Antropológicos, percebe-se que o conceito de tecnologias de governo tem vindo a assumir uma natureza camaleônica. A sua plasticidade permite dotá-lo de significados distintos e, algumas vezes, contraditórios. A presente coletânea assume em plenitude essa hibridez e ambivalência, apresentando itinerários para repensar e etnografar modos de regulamentação dos corpos, das populações e das subjetividades. Os estudos aqui incluídos são deliberadamente transgressivos num gênero de hibridez epistêmica que exige do pesquisador que se enrede nos conteúdos e problemas "internos" às práticas dos seus objetos (Law, 2004; Mol, 2004). Contudo, não é inadequado afirmar que aqui se partilha uma base mínima de entendimento de uma etnografia sensível à intimidade das relações entre pessoa, objetos, corpos e estruturas organizacionais, bem como aos processos da sua mútua constituição. Trata-se de pensar as tecnologias de governo como 
conjuntos de atividades práticas, produtos locais de trabalhos coletivos de grupos heterogêneos de atores, humanos e não humanos.

Um aspeto importante dessas atividades práticas é o enredamento do corpo numa teia de mediações que produzem um denso coletivo de arranjos materiais, emotividade, imersões políticas e proposições articuladas (Latour, 2004). Distanciando-se de uma noção de corpo integral e delimitado, alguns dos trabalhos desta coletânea fornecem pistas para pensar uma "antropologia simétrica", na qual tanto humanos como não humanos detêm agência (Latour, 1993), assim como recombinações de biopolítica que operam a partir do corpo e para além das fronteiras do corpo.

“"Não tem corpo, não tem crime': notas socioantropológicas sobre o ato de fazer desaparecer corpos", um estudo de Fábio Alves Araújo, que abre este número, é exemplar das múltiplas ontologias que o corpo pode assumir, ao mostrar como a categoria "pessoas desaparecidas" pode ser performada para ganhar significados e materialidades distintas consoantes os contextos locais e configurações de sentido atribuídos pelos atores sociais (Law, 2009). A dupla condição da negativa do Estado em disponibilizar dados para o pesquisar, ao mesmo tempo em que o etnógrafo analisa a tecnologia de poder operada pela polícia na gestão de ocorrências de pessoas desaparecidas, representa um exemplo dos modos como a lei é um mecanismo de ordenação social que envolve objetos, atores e contextos organizacionais. A teoria do realismo agencial proposta pela antropóloga feminista Karen Barad (2007), como uma forma de pensar a impossibilidade de separar o material do sociocultural, ajuda-nos a perspectivar o desaparecimento de pessoas e como estes criam processos relacionais, pelos quais os corpos não existem como algo dado, pré-delimitado, mas são continuamente materializados pelas ações performativas e atribuições de sentido construídas e performadas pelos atores (Kruse, 2010). Araújo mostra o enredamento entre distinções de categorias e de campos de ação para tratar as disputas entre vítimas, familiares, mídia e políticos, apresentando o desaparecimento de pessoas como um "objeto impuro" (Nunes; Roque, 2008).

Uma antropologia das impurezas, orientada por uma dimensão material-semiótica nos termos sugeridos por Donna Haraway (1997), é desvendada no estudo "Entre estupros e convenções narrativas: os Cartórios Policiais e seus papéis numa Delegacia de Defesa da Mulher (DDM)" de Larissa Nadai, o segundo artigo deste número, versa sobre as convenções narrativas de estupro 
elaboradas em cartórios policiais. Os modos de narrar pelos papéis embalam subjetividades e legibilidades que na ótica da noção de dimensão material-semiótica proposta pela filósofa feminista estende o conceito de semiótica para uma ontologia relacional (Haraway, 1997) que sai da linguagem para a construção de uma realidade na qual os sentidos posicionados, expertise, objetos, burocracia e leis comaterializam narrativas e verdade legíveis (Latour, 2010).

O artigo de Daniel Hirata e Bruno Cardoso, "Coordenação como tecnologia de governo" (neste número) trata da produção de ordem urbana por via de controle tecnológico à distância, fazendo o mapeamento de redes e fluxos de relações nos quais a performatividade da mediação tecnológica assume uma dimensão agencial central. Tal dimensão revela trajetórias sustentadas em processos sociais de globalização e desenvolvimento exponencial de recursos informáticos e tecnológicos próprios da chamada sociedade da informação (Castells, 1998) e dialoga de modo muito claro com aquilo que Foucault (2003, p. 249) designa por "tecnologias de segurança". Estas se referem a tecnologias de governo associadas a modos de controle regulatório da população que vão além da mera disciplina e supervisão, mas antes visam atingir um equilíbrio que permita proteger a segurança do todo em relação aos perigos internos, em que o indivíduo e as massas são os dois lados de uma tecnologia política global no âmbito de uma economia política do conhecimento orientada para a burocratização racional (Foucault, 2003, p. 242-243). Na perspectiva das teorias da sociedade do risco (Beck, 1992; Beck; Giddens; Lash, 2000), esses mecanismos de controle social aceleraram uma reconfiguração dos mecanismos clássicos de controle da ordem pública que enraízam conhecimento construído sobre as populações num tipo de linguagem traduzível e legível por máquinas e transmissível em padrões de informação que se organizam em "pacotes" mobilizáveis por diversos agentes de controle social, em coerência com dispositivos burocráticos do Estado (Machado; Santos, 2016).

\section{Onde reside o poder? Os miúdos materiais das tecnologias}

$\mathrm{Na}$ abordagem em que apostamos aqui, há, por um lado, uma convicção de que, por motivos analíticos e políticos, é fundamental "esmiuçar" as dinâmicas de governo, rastrear seus elos concretos enquanto elementos firmemente situados no tempo e no espaço. Por outro lado, existe certa urgência em ressaltar a materialidade desses processos justamente para melhor entender 
onde reside o poder, isto é, onde e como as decisões que governam a vida do cidadão comum são elaboradas e implementadas.

Podemos exemplificar a importância dessa abordagem através do tema contravertido do aborto. Em 2015, veio à atenção dos leitores dos jornais nos Estados Unidos o fato de que o direito ao aborto, longamente debatido nos tribunais, sacramentado pela Corte Suprema em 1973 e festejado por feministas e progressistas, estava sendo sub-repticiamente derrubado. $\mathrm{O}$ mecanismo que tinha fechado mais do que a metade das clínicas que tinham proliferado no afã da legalização do aborto nada tinha a ver com a lei. Tinha a ver com as secretarias estaduais de Saúde que, sob pretexto de zelar pelo bem-estar das mulheres, faziam cobranças infraestruturais cada vez mais exigentes às unidades que realizavam abortos. Já que o congresso conservador tinha banido o aborto da lista de procedimentos apoiados pela saúde pública, as mulheres não tinham mais recurso a hospitais públicos. Pelos novos regulamentos sanitários implementados pelos estados, as pequenas clínicas estavam sendo obrigadas a manter um equipamento equivalente a um bloco cirúrgico de emergência ou, na falta desse, travar acordos com um hospital nas redondezas que dispunha do instrumental adequado. Já que a grande maioria dos hospitais privados é confessional, as chances de poder travar tal acordo eram, na maioria de casos, escassas. O resultado: em estados - como o Texas - que impuseram as exigências "sanitárias", o aborto legal se torna inacessível a boa parte das mulheres (Fessenden, 2016).

É impossível o leitor desses fatos não se perguntar: onde reside o poder de regular o comportamento dos cidadãos? Estariam nas lutas legislativas e grandes projetos estatais repetidamente destacados tanto nos manchetes da grande mídia quanto nos debates da pesquisa acadêmica? Ou residiriam nos detalhes miúdos da regulação administrativa da infraestrutura (burocrática, laboratorial, logística) desses esquemas - assunto que, em comparação, atrai pouca atenção? Reduzir, nas nossas análises, o poder à parte mais visível desses processos não seria confundir o espetáculo do poder com sua operacionalização? É essa confusão que, conforme o antropólogo Akhil Gupta (2012), levaria a uma visão equivocada das dinâmicas políticas de governo, subestimando a força dos processos burocráticos e de suas consequências sociais. Esse tipo de visão reificada do Estado e das entidades do poder instituído teria consequências problemáticas para o pensamento acadêmico, mas seu efeito mais nefasto seria na formulação e implementação de políticas públicas. 
A imagem de Arquimedes que, graças à polia composta, consegue deslocar um enorme navio de transporte cheio de homens serve para sublinhar a importância fundamental das mediações mecânicas na queda de braços entre adversários. Nas mãos hábeis de Bruno Latour (1993) essa anedota sublinha o potencial que tem um gesto mínimo, tranquilo e geograficamente distante de seu objeto para tornar um só indivíduo mais forte do que uma multidão. De modo análogo, sugerimos que, muitas vezes, o impacto mais consequente de uma política pública reside menos nos grandiosos princípios badalados nas cartilhas do que nos detalhes "meramente técnicos" de sua implementação.

A definição dos instrumentos usados para descrever e medir a realidade-alvo de intervenção é delegada, em geral, aos experts científicos. Contudo, são muitos os exemplos na literatura antropológica de como um pequeno ajuste nos instrumentos científicos pode provocar uma reviravolta na nossa percepção do problema a ser confrontado: pelo uso de um novo software, áreas desmatadas "reveladas" por imagens de satélite são transformadas em mata (Monteiro, 2016); por um leve deslocamento de parâmetro na definição de grupos de controle, ensaios clínicos "baseados em evidências" podem confirmar a inocuidade de um remédio, até então, classificado como arriscado (Adams, 2013); por uma reformulação de categorias analíticas, a taxa de homicídio pode baixar sem que haja qualquer mudança de comportamento (Fábio Alves Araújo, neste número).

De maneira semelhante, observamos em artigos aqui reunidos como o efeito do saber antropológico se altera em função do lugar que ocupa na engrenagem do processo administrativo. Em "Tecnologias de governo, regularização de territórios quilombolas, conflitos e respostas estatais", Ana Paula Comin de Carvalho (neste número) descreve como, no bojo de embates entre "terras de preto", reservas extrativistas e a implantação de um estaleiro voltado para a indústria petroleira, que o destino de certas comunidades pesqueiras é selado por um pequeno ajuste no mapa administrativo. Por outro lado, Thais Mantovanelli (neste número), escrevendo sobre "Os Xikrin da Terra Indígena Trincheira-Bacajá e os Estudos Complementares do Rio Bacajá: reflexões sobre a elaboração de um laudo de impacto ambiental", mostra como - não obstante a mediação antropológica - os conhecimentos e a "voz" dos povos indígenas são paulatinamente eliminados do relatório final. Este, por razões "técnicas", privilegia uma estética de gráficos e cálculos matemáticos. A lição 
solidamente reiterada nesses estudos é que não existem "meros" detalhes técnicos. Para entender o funcionamento da máquina estatal, analistas devem considerar não só as arenas públicas de confronto assumidamente político, mas também (e, talvez, em prioridade) os elos relativamente "invisíveis" dos meandros administrativos do poder.

\section{Burocracias: mediacõos e intermediários}

Enquanto alguns analistas se voltam para os efeitos políticos dos processos administrativos, outros procuram aprofundar sua compreensão do próprio aparato burocrático. Isto é, em vez de estudar como as tecnologias de governo afetam determinadas coletividades identificadas como singulares e interpeláveis pelo Estado-nação, ampliam o escopo da investigação, submetendo a exame a própria noção que comumente manejamos de "burocracia". Reconhecida inicialmente como aquilo que corporifica as "lógicas administrativas", é relatada e vivida ora como "um dano", ora como uma "lente redutora" (Jardim, 2015; Tiscornia, 2004). Entretanto, dificilmente tais lógicas poderiam ser visualizadas sem perceber o quanto estão permeadas por saberes jurídicos e procedimentos impregnados de sentidos de objetividade e cientificidade, ancoradas em formas de inspecionar e criar "certezas" daqueles que delas se dizem tributários e impregnados das exigências tão "naturalizadas" das tecnologias de governo.

Assim, se inicialmente, assume-se a "burocracia" como aquilo que daria "corpo" ao Estado, é através da etnografia que a vislumbramos permeada por diversos saberes, empurrada por circunstâncias e negociação de sentidos, mostrando que sua resistência ao mundo é também uma tentativa constante em se autoproclamar resistente. Signos diversos podem expressar a burocracia. Como lembra Tiscornia (2004), a linguagem jurídica, a letra impressa, a materialidade que escolhe é uma possibilidade de conferir modos de objetivar o intangível da experiência humana. São esses elementos, negociáveis sob certas condições, que seguem perseguindo os antropólogos em campo, especialmente aqueles que através da etnografia vislumbram o fato inventivo produzido na relação entre atores acerca da "realidade" que os dispositivos de poder oferecem para quantificar, classificar pessoas, recepcionar e encorajar a "bons comportamentos". 
No artigo de Beatriz Padilla e Francisco José Cuberos-Gallardo (neste número), "Deconstruyendo al inmigrante latinoamericano: las políticas migratorias ibéricas como tecnologías neocoloniales" encontramos uma reflexão sobre a roupagem atual das noções de "assimilação" e "integração" de imigrantes nas políticas públicas, que prioriza as noções de proximidades linguísticas e religiosas como base da seletividade e redução da pluralidade dos imigrantes a uma diversidade palatável capaz de preencher noções de "compatibilidade" cultural. Como propõe o artigo de Iban Trapaga (neste número), "Etnopolítica mexicoamericana en Houston y nuevos inmigrados", os estudos sobre "novos imigrantes" nos conduzem a uma reflexão sobre os discursos e saberes, como são corporificados pelos trabalhadores sociais, professorado e administradores que manejam as políticas de recepção a novos migrantes, evidenciando o tenso diálogo permeado por contraposições e elaborações dos "sujeitos-alvo" de tais políticas. Nesse caso, as tecnologias, antes de serem aqui consideradas em sua formalidade, são examinadas por exercerem enorme influência sobre o imponderável da vida humana.

As tecnologias de identificação pessoal - nomes de família, fotos, documentos de identidade, passaportes, impressões digitais, perfis de DNA - constam como objeto de muitos dos primeiros estudos sobre o esforço do Estado moderno de garantir a legibilidade da população (Fonseca; Machado, 2015; Torpey, 2003). Mas a produtividade dos "papéis" vai muito além da identificação (ver, por exemplo, Lowenkron; Ferreira, 2014). Gupta (2012, p. 23, tradução nossa), no seu estudo do "red tape" de políticas sociais na Índia, reitera o enorme poder dos processos administrativos: "[...] não importa quão nobres as intenções dos programas, não importa quão sinceros os técnicos carregados de realizá-los, o objetivo explícito de ajudar os pobres é subvertido pelos próprios procedimentos da burocracia”. Contudo, tal como Hull (2003) debruçado sobre documentos burocráticos no Afeganistão, Gupta procura dar visibilidade aos elos "mediadores" da administração que, longe de seguir mecanicamente esquemas top-down de disciplinamento e controle, se revelam como artefatos com consequências nem sempre previsíveis.

A legibilidade da população entrelaçada à legitimidade desta em permanecer e percorrer territórios é uma das intencionalidades das técnicas de identificação que se expressa de modo contundente nas trajetórias imigrantes. $\mathrm{O}$ artigo de Denise F. Jardim (neste número), "Imigrantes ou refugiados? As tecnologias de governamentalidade e o êxodo palestino rumo ao Brasil no 
século XX”, inspeciona uma quase inaudível realidade sobre a experiência migratória: a luta em torno da autoclassificação e definição administrativa. A autora demonstra claramente como as trajetórias de imigrantes palestinos são constrangidas por regras constantemente mudadas de residência e cidadania nos países que poderiam os acolher Porém, ao mesmo tempo evidencia-se na descrição etnográfica dos residentes no Brasil um aprendizado contínuo sobre como lidar com opções "jurídico-burocráticas" cambiantes e frequentemente desfavoráveis.

A analítica que persegue tal entendimento pode ser percebida em outros estudos sobre a constituição da burocracia e processos de construção dos Estados, os quais enfatizam a importância dos intermediários humanos. A grossa simplificação de complexas realidades operada pela linguagem abstrata dos projetos estatais modernistas já foi amplamente comentada, em particular, por James Scott (1998). Mas, conforme Michael Herzfeld (2005), mesmo um analista tão brilhante quanto Scott acaba caindo na cilada da dicotomia techne (representando a racionalidade estatal) versus métis (jeitinho) popular. Os dois autores têm em comum a ideia de que o "jeitinho" faz parte da lógica modernista: a rigidez das regras burocráticas pressupõe a flexibilidade de sua aplicação: "Repetidas vezes, o Estado e suas instituições foram salvos das consequências de sua visão monocromática pela capacidade de pessoas comuns enjambrarem [as coisas], dar um jeito ou simplesmente aguentar [a situação]" (Herzfeld, 2005, p. 372, tradução nossa).

Mas Herzfeld considera que Scott deixou fora da análise um elemento fundamental: os intermediários - isto é, os burocratas - cuja função é correr o meio de campo entre as regras estatais e as pessoas comuns. $\mathrm{O}$ autor avança um programa de "etnografia crítica" desses intermediários, capaz de revelá-los como pessoas pensantes, muitas das quais compartilhando as circunstâncias de vida de seus clientes e preocupadas em melhor servir a população. Estudar os jeitinhos dos funcionários públicos em relação às regras que devem aplicar e a "cumplicidade pragmática" com os usuários do sistema não só ajuda a derrubar visões dicotômicas, também explora as necessárias zonas de facilidade familiar (familiar ease) que permitem o ajuste dos cânones oficiais ao vivido da experiência social (Herzfeld, 2005, p. 372).

As observações de Herzfeld dialogam de forma interessante com a visão crítica de Fassin (2009) sobre a noção foucaultiana da "arte de governar". Conforme essa crítica, o autor clássico emprega "arte" no sentido comum 
entre filósofos do século XVII - enquanto mentalidade ou racionalidade do Estado. Fassin propõe deslocar o olhar analítico dos princípios para as práticas dessa "arte" - práticas repletas de personagens concretos, com afetos e emoções. Nessa perspectiva, o objeto de análise não seria tanto as "regras do jogo" (jeux) quanto as apostas (enjeux) e a "ginga" dos jogadores.

$\mathrm{Na}$ análise de Isabele Villwock Bachtold (neste número) intitulada "Quando o Estado encontra suas margens: considerações etnográficas sobre um mutirão da estratégia de Busca Ativa no estado do Pará", encontramos um exemplo dessa "ginga" dos intermediários. Sua descrição sobre a "busca ativa", visando garantir direitos sociais a populações carentes ao longo de um afluente do rio Amazonas, destaca o lugar dos próprios documentos escritos na mediação de relações entre os Estado e suas "margens". Ao vencer os diversos obstáculos burocráticos para se inscrever no Cadastro Único e ter acesso aos benefícios sociais, as pessoas entram nas estatísticas que garantem a "legibilidade" da população. Ao mesmo tempo, esses artefatos gráficos contribuem para a construção ritual da autoridade de agentes individuais e coletivos do Estado (Hull, 2003). Mas, nesse processo, o que mais se destaca na descrição etnográfica é a flexibilidade do sistema assegurada pela ousadia dos funcionários federais e locais empenhados em levar não só benefícios, mas também moralidades de cidadania para o interior do país.

De modo semelhante, o artigo "“A sociedade brasileira nos fez pobres': assistência social e autonomia étnica dos povos indígenas. $\mathrm{O}$ caso de Dourados, Mato Grosso do Sul" de Júlio César Borges (neste número), ao observar o funcionamento do primeiro CRAS indígena do país (em Dourados, MS), destaca como, do ponto de vista dos profissionais da área, fazem falta orientações, capacitações e manuais voltados especificamente para a população indígena. Apesar da "dimensão simbólica" do atendimento especializado ser plenamente posta na doutrina escrita, ainda faltam meios para passar à "dimensão operativa" dessas políticas. Entretanto, ao incorporar na equipe de atendimento pessoas indígenas, introduz-se uma série de ajustes no sistema (incluindo a ressignificação de categorias tais como "vulnerabilidade", "risco social", etc.). Nesse processo, não só os técnicos de referência indígenas se tornam elos criativos, fundamentais para alcançar ou readequar as metas da política, o próprio motorista da equipe do CRAS, sendo capitão da aldeia Bororó, também assume uma importância central nessas tecnologias de governo. 


\section{Sujeitos e suas agências em processos dinâmicos de coproducão}

Nesse processo de canibalização, pela antropologia, do interesse em relação às tecnologias de governo, a própria transcendência da noção de sujeito também é colocada em causa, possibilitando renovações importantes da clássica argumentação foucaultiana em relação aos processos de sujeição-subjetivação, assim como tematizações menos abstratas em relação às dinâmicas da agência e resistência. Ao contrário de essencialismos, o interesse passa a ser o de compreender processos dinâmicos de coprodução que relacionam sujeitos, saberes, objetos, práticas e estruturas organizacionais. Longe de querer resolver tais questões ou mesmo dissecá-las em maior detalhe, importa referir certo consenso antropológico da dimensão que os sujeitos têm, na associação com outros atores humanos e não humanos, na configuração das práticas de governo. Esse esforço argumentativo vem sendo realizado não apenas através da vitalidade dos dados e experiências dos sujeitos trazidos pelas etnografias, mas também através de renovações conceituais importantes nesse campo de debates.

No que diz respeito às pesquisas antropológicas, alguns trabalhos contemporâneos se interessam em discutir as dinâmicas da relação entre as formas de constituição de sujeitos e práticas de agência e resistência. O historiador Michel de Certeau (1980), como um analista das tramas cotidianas, contribuiu nesse âmbito de problematizações ao acentuar as possibilidades de leitura de formas de resistência às expressões de disciplinamento. Certeau (1980) aponta a relevância das táticas e estratégias de resiliência, assim como as reapropriações criativas dos atores em torno de brechas presentes nos dispositivos de disciplinamento e de normalização que, por sua natureza eminentemente difusa e múltipla, dificilmente têm um efeito totalitário.

$\mathrm{Na}$ mesma direção da acentuação analítica das táticas e estratégias de resistência, a pesquisa de Ong (2003) acerca dos refugiados cambojanos nos Estados Unidos é um exemplo, ao abordar as tecnologias de governo empreendidas no esforço em transformar refugiados cambojanos em cidadãos americanos. Tecnologias de poder são definidas, por Ong (2003), como um conjunto diverso de políticas, programas, códigos e práticas que tentam instalar em cidadãos-sujeitos certos valores (como autoconfiança, liberdade, individualismo, etc.) em uma variedade de domínios. $\mathrm{O}$ interessante de sua perspectiva 
é que, ao invés de definir cidadania somente em termos de um poder estatal, Ong (2003) analisa as práticas e políticas sociais para além do Estado, em uma miríade de formas de definir, sugerir e dirigir à aderência as normas democráticas, raciais e mercadológicas de pertencimento. Longe de afirmar a impotência dos refugiados na sujeição à variedade dos regimes de regulação que este processo engendra, Ong (2003, p. 17) destaca que as suas táticas e estratégias de negociação são essenciais para a compreensão dos processos estudados:

Indeed, Foucault has argued that regulatory programs "never work out as planned", not only because different strategies may be opposed, but because subjects interpret and act in ways that undo systems of classifications (cultural, ethnic, moral), refuse different kinds of objectives (involving needs, desires, behavior) and thwart rules of surveillance and punishment.

Nesta coletânea, o artigo de Valéria Aydos, intitulado "Agência e subjetivação na gestão de pessoas com deficiência: a inclusão no mercado de trabalho de um jovem diagnosticado com autismo" acentua a associação entre as formas de interpretação dos atores e suas transformações subjetivas na interação com tecnologias de governo. Detém-se, especialmente, nas experiências de um jovem diagnosticado como autista, realizadas em meio às tecnologias médicas, governamentais e mercadológicas que lhe permitem acessar o mercado de trabalho. A partir do ponto de vista das experiências do menino Tomás, Aydos atenta para o que Michel Foucault chamou de "práticas de subjetivação" (Foucault, 2008), buscando compreender como o menino habita as categorias morais, médicas e governamentais a ele atribuídas e como é capaz de agir sobre elas e a partir delas, na interação com os diversos atores humanos e não humanos com quem se relaciona.

O artigo de Carla Gallinati (neste número) "La participación política de bolivianos y paraguayos residentes de villas en la ciudad de Buenos Aires: una aproximación desde la lucha por la vivienda" também frequenta essa gama de questões buscando evidenciar protagonistas e tensões que presidem a luta de imigrantes por alcançar visibilidade diante das políticas relativas a habitação. Tal como na situação descrita acima para Tomás, Gallinati descreve como as pessoas, jogando com diferentes identidades possíveis - nesse caso, nacional, popular, étnica - interagem criativamente com as categorias morais embutidas nas políticas públicas cunhadas para elas. 


\section{Uma etnografia das tecnologias de governo?}

Entre os saberes que enunciam e examinam os imponderáveis das tecnologias de governo, onde se situam os antropólogos? Mesmo que fortemente influenciados pela proposta foucaultiana na qual são levados a conceber um intrincado jogo de forças, os antropólogos, desfrutando de uma longa experiência disciplinar com etnografia, criavam trilhas originais para o estudo do entrecruzamento entre saberes e poderes. Não é por acaso que dois antropólogos tidos como referência nesse campo temático - Fassin e Biehl têm a etnografia como ferramenta central de suas análises. Hoje, não obstante críticos (Ingold, 2014), há certo consenso de que faz sentido guardar e estender a ideia de etnografia para "novos" objetos tais como saberes científicos, diagnósticos médicos, cadastros de gestores públicos, burocracias policiais, regulamentos territórios, políticas de segurança, formas de coordenação organizacional, etc.

Por um lado não há dúvida de que a perspectiva etnográfica tem enriquecido estudos normalmente restritos a técnicas clássicas de história e administração. Ao encarar a pesquisa em instâncias institucionais de poder como um estudo etnográfico de campo, antropólogos têm explorado "o conhecimento de que o Estado necessita” (Dirks, 2001 apud Cunha, 2004, p. 292): "temporalidades múltiplas inscritas em eventos e estruturas sociais [...] subsumidas à cronologia da história por meio de artifícios classificatórios" e transformadas em narrativas que canonizam o repositório "neutro" do passado (Cunha, 2004, p. 292). Por outro lado, essa experiência de etnografia realizada em contextos pouco convencionais tem provocado um redimensionamento metodológico dentro da disciplina da antropologia, isto é, uma releitura e reordenamento da própria prática etnográfica.

Por exemplo, ao descrever o "encantamento" dos antropólogos com a linguagem jurídica, Tiscornia (2004) frisa a necessidade de o analista entender que - ao decifrar dispositivos de poder - deve levar em consideração como ele ou ela também é "falante" desse idioma. Nesse caso, para o etnógrafo, manter uma vigilância epistemológica que repercute em sua capacidade de lançar questionamentos é mais do que nunca parte do ofício. E ainda, como tantos autores neste número indagam, quando trabalhamos com um tema, somos tão somente analistas? Ou já comungamos de tal idioma - das tecnologias de 
governo - sendo iniciados em suas lógicas e pressupostos, prontos para formular as pautas de sua plena realização?

Sugerimos que existe um processo em curso que sublinha a possibilidade de promover "a etnografia como técnica de resposta" (Riles, 2008, p. 16, tradução nossa). Isso significa, a partir da análise de artefatos encontrados no campo, entrar em diálogo crítico com as abordagens teóricas usuais, não no espírito de denúncia, mas no espírito de interagir e ir além delas. Significa desenvolver análises do campo não através de orientações canônicas ou por dedução teórica e, sim, "lateralmente, através da apreensão etnográfica e/ou empatia" (Riles, 2008, p. 17, tradução nossa), processo que "responde" às preocupações das diferentes "plateias" da pesquisa (incluindo os interlocutores no campo, outros pesquisadores, vetores da "opinião pública" e o próprio etnógrafo). Finalmente, como vemos em certos dos textos neste número, uma "etnografia responsiva" também poderia ser entendida no sentido de uma etnografia responsável - em que o pesquisador questiona e assume plenamente a responsabilidade pelos efeitos do conhecimento que ele próprio está produzindo.

Nesse espírito, propomos que os artigos aqui reunidos demonstram como, no estudo dos variados campos de intervenção político-social voltados para a promoção do "bem-estar das populações", o etnógrafo é capaz de levantar elementos novos e surpreendentes. Pela etnografia das diversas mediações que operam na construção, implementação e recepção de políticas de intervenção - que envolvam a administração estatal, organizações não governamentais, movimentos ou associações, em escala nacional ou internacional - é possível observar como as políticas são transformadas na prática pelos diversos atores que compõem o cenário. No processo, fica claro o caráter produtivo das tecnologias que, entre seus diversos efeitos, criam novas normatividades e modos de atuação política. $\mathrm{O}$ efeito acumulado dos artigos deste número de Horizontes Antropológicos, pelo exame insistente dos gestos miúdos e materiais de processos políticos em contextos situados, é (re)afirmar o lugar indispensável da perspectiva etnográfica para uma sofisticação das grandes preocupações políticas de nossa época.

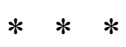

Horizontes Antropológicos, Porto Alegre, ano 22, n. 46, p. 9-34, jul./dez. 2016 
O Espaço Aberto apresenta, além da já comentada entrevista com João Biehl, o artigo de Gláucia Silva e Luiz Fernando Dias Duarte, "Epigênese e epigenética: as muitas vidas do vitalismo ocidental".

A figura humana que escolhemos para a capa deste número é de autoria de Giuseppe Arcimboldo, pintor renascentista italiano que viveu em Milão no século XVI e que ficou conhecido pelos exercícios de recomposição do humano através de objetos diversos. O bibliotecário emerge da sobreposição de livros e representa uma potente imagem sobre os múltiplos registros, documentos e formas criativas de inscrever a experiência humana nas tecnologias de governo.

\section{Referências}

ABU-LUGHOD, L. Writing against culture. In: FOX, R. (Ed.). Recapturing anthropology. Santa Fe: School of American Research, 1991. p. 137-162.

ADAMS, V. Evidence-based global public health: subjects, profits, erasures. In: BIEHL, J.; PETRYNA, A. (Ed.). When people come first: critical studies in global health. Princeton: Princeton University Press, 2013. p. 55-90.

ASAD, T. Introduction. In: ASAD, T. (Ed.). Anthropology and the colonial encounter. New York: Humanities, 1973. p. 1-33.

BARAD, K. Meeting the university halfway: quantum physics and the entanglement of matter and meaning. Durham: Duke University Press, 2007.

BECK, U. Risk society: towards a new modernity. New Delhi: Sage, 1992.

BECK, U.; GIDDENS, A.; LASH, S. Modernização reflexiva: política, tradição e estética no mundo moderno. Oeiras: Celta, 2000.

BIEHL, J. Antropologia do devir: psicofármacos - abandono social - desejo. Revista de Antropologia, São Paulo, v. 51, n. 2, p. 413-449, 2008.

BIEHL, J.; ESKEROD, T. Vita: life in a zone of social abandonment. Berkeley: California University Press, 2005. 
BIEHL, J.; ESKEROD, T. Will to live: AIDS therapies and the politics of survival. Princeton: Princeton University Press, 2007.

BIEHL, J.; LOCKE, P. Deleuze and the anthropology of becoming. Current Anthropology, Chicago, v. 51, n. 3, p. 317-351, June 2010.

CASTELLS, M. End of Millennium: the information age: economy, society and culture vol. III. Cambridge: Blackwell, 1998.

CERTEAU, M. L'invention du quotidien. Paris: Gallimard, 1980.

CUNHA, O. M. G. da. Tempo imperfeito: uma etnografia do arquivo. Mana, Rio de Janeiro, v. 10, n. 2, p. 287-322, 2004.

DAS, V.; POOLE, D. State and its margins. In: DAS, V.; POOLE, D. (Ed.). Anthropology in the margins of the state. Santa Fe: School of American Research Press, 2004. p. 3-33.

DELEUZE, G. As dobras, ou o de dentro do pensamento (subjectivação). In: DELEUZE, G. Foucault. Lisboa: Vega, 1987. p. 127-163.

DELEUZE, G. Désir et plaisir. Magazine Littéraire, Paris, n. 325, p. 57-65, oct. 1994.

DELEUZE, G. O que é um dispositivo?. In: DELEUZE, G. O mistério de Ariadne. Lisboa: Vega, 1996. p. 83-96.

DIRKS, N.; ELEY, G.; ORTNER, S. (Ed.). Culture/Power/History: a reader in contemporary social theory. Princeton: Princeton University Press, 1993.

FABIAN, J. O tempo e o outro emergente. In: FABIAN, J. O tempo e o outro: como a antropologia estabelece seu objeto. Petrópolis: Vozes, 2013. p. 39-70.

FASSIN, D. When bodies remember: experiences and politics of AIDS in South Africa. Berkeley: University of California Press, 2007a.

FASSIN, D. Humanitarianism as a politics of life. Public Culture, Durham, v. 19 , n. 3, p. 499-520, 2007 b. 
FASSIN, D. Beyond good and evil? Questioning the anthropological discomfort with morals. Anthropological Theory, London, v. 8, n. 4, p. 333345, 2008.

FASSIN, D. Another politics of life is possible. Theory, Culture and Society, London, v. 26, n. 5, p. 44-60, 2009.

FASSIN, D. La raison humanitaire: une histoire morale du temps présent. Paris: Seuil: Gallimard, 2010.

FASSIN, D. La force de l'ordre: une anthropologie de la police des quartiers. Paris: Seuil, 2011.

FASSIN, D. Introduction: towards a critical moral anthropology. In: FASSIN, D. (Ed.). A companion to moral anthropology. Oxford: Wiley-Blackwell, 2012. p. 1-17.

FASSIN, D.; PANDOLFI, M. Contemporary states of emergency: the politics of military and humanitarian interventions. New York: Zone Books, 2010.

FESSENDEN, F. How the Supreme Court case could change women's access to abortion. The New York Times, New York, 29 Feb. 2016. Disponível em: $<$ http://nyti.ms/1RAxrDn>. Acesso em: 29 fev. 2016.

FONSECA, C.; MACHADO, H. (Org.). Ciência, identificação e tecnologias de governo. Porto Alegre: Editora da UFRGS: CEGOV, 2015.

FOUCAULT, M. A governamentalidade. In: FOUCAULT, M. Microfisica do poder. Rio de Janeiro: Graal, 1979. p. 277-293.

FOUCAULT, M. Vigiar e punir: história de violência nas prisões. Petrópolis: Vozes, 1987.

FOUCAULT, M. Society must be defended: lectures at the Collège de France, 1975-76. New York: Picador, 2003.

FOUCAULT, M. O nascimento da biopolítica. São Paulo: Martins Fontes, 2008. 
GUPTA, A. Red tape: bureaucracy, structural violence, and poverty in India. Durham: Duke University Press, 2012.

HARAWAY, D. Simians, cyborgs and women: the reinvention of nature. New York: Routlegde, 1991.

HARAWAY, D. Modest_Witness@Second_Millennium.FemaleMan@_Meets_ OncoMouse ${ }^{\mathrm{TM}}$ : feminism and technoscience. New York: Routledge, 1997.

HERZFELD, M. Political optics and the occlusion of lntimate knowledge. American Anthropologist, Arlington, v. 107, n. 3, p. 369-376, 2005.

HULL, M. S. The file: agency, authority, and autography in an Islamabad bureaucracy. Language \& Communication, Oxford, v. 23, n. 3-4, p. 287-314, 2003.

INGOLD, T. That's enough about ethnography. HAU: Journal of Ethnographic Theory, Edinburgh, v. 4, n. 1, p. 383-395, 2014.

JARDIM, D. F. Os caminhos do cadastro e outros obstáculos da visibilização do imigrante no Brasil. In: FONSECA, C.; MACHADO, H. (Org.). Ciência, identificação e tecnologias de governo. Porto Alegre: Editora da UFRGS: CEGOV, 2015. p. 76-95.

KRUSE, C. Forensic evidence: mMaterializong bodies, materializing crimes. European Journal of Women's Studies, Thousand Oaks, v. 17, n. 4, p. 363-377, 2010.

LATOUR, B. We have never been modern. Cambridge: Harvard University Press, 1993.

LATOUR, B. How to talk about the body? The normative dimension of science studies. Body and Society, London, v. 10, n. 2-3, p. 205-229, June 2004.

LATOUR, B. Reassembling the social: an introduction to actor-network theory. Oxford: Oxford University Press, 2005.

LATOUR, B. The making of law. an ethnography of the Conseil d'Etat. Cambridge: Polity Press, 2010. 
LAW, J. After method: mess in social research. London: Routledge, 2004.

LAW, J. Actor network theory and material semiotics. In: TURNER, B. S. (Ed.). The New Blackwell Companion to Social Theory. Oxford: Blackwell, 2009. p. 141-158.

LOWENKRON, L.; FERREIRA, L. Anthropological perspectives on documents. Ethnographic dialogues on the trail of police papers. Vibrant, Brasília, v. 11, n. 2, p. 75-111, 2014.

MACHADO, H.; SANTOS, F. Culturas de objetividade, epistemologias cívicas e o suspeito transnacional. Uma proposta para mapeamentos teóricos em estudos sociais da genética forense. In: FONSECA, C. et al. (Org.). Antropologia da ciência e da tecnologia: dobras reflexivas. Porto Alegre: Sulina, 2016. p. 179-203.

MITCHELL, T. Society, economy and the state effect. In: STEINMETZ, G. (Ed.). State/culture: state-formation after the cultural turn. New York: Cornell University Press, 1999. p. 76-97.

MOL, A. The body multiple. Durham: Duke University Press, 2004.

MONTEIRO, M. Politizando incertezas: o sensoriamento remoto e o desmate no Brasil. In: FONSECA, C. et al. (Org.). Antropologia da ciência e da tecnologia: dobras reflexivas. Porto Alegre: Sulina, 2016. p. 119-148.

NUNES, J.; ROQUE, R. Objectos impuros: experiências em estudos sobre a ciência. Porto: Afrontamento, 2008.

ONG, A. Buda is hiding: refuges, citizenship and the New America. Berkeley: University of California Press, 2003.

ONG, A.; COLLIER, S. Global assemblages, anhropological problems. In: ONG, A.; COLLIER, S. (Ed.). Global assemblages: technology, politics and ethics as anthropological problems. Oxford: Blackwell, 2005. p. 3-21.

RILES, A. In response. In: RILES, A. (Ed.). Documents: artifacts of modern knowledge. Ann Arbor: University of Michigan Press, 2008. p. 1-38. 
ROSE, N. Powers of freedom: reframing political thought. Cambridge: Cambridge University Press, 1999.

SAID, E. Orientalismo: o Oriente como invenção do Ocidente. São Paulo: Companhia das Letras, 1990.

SCOTT, J. Seeing like a state: how certain schemes to improve the human condition have failed. New Haven: Yale University Press, 1998.

SHARMA, A.; GUPTA, A. Rethinking theories of the state in the age of globalization. In: SHARMA, A.; GUPTA, A. The anthropology of the state: a reader. Oxford: Blackwell, 2006. p. 1-41.

TISCORNIA, S. (Comp.). Burocracias y violencia: estúdios de antropologia jurídica. Buenos Aires: Antropofagia, 2004.

TORPEY, J. A invenção do passaporte: vigilância, cidadania e o Estado. Lisboa: Temas e Debates, 2003. (Coleção Memórias do Mundo). 